\title{
Retroinnovación y sustentabilidad socioecológica: el caso de quesos campesinos de leche cruda en el Golfo de Arauco, Chile
} \author{
sustainability \\ Beatriz Cid-Aguayo \\ Universidad de Concepción, Departamento de Sociología, \\ Chile \\ beatrizcid@udec.cl \\ Julien Vanhulst \\ Universidad Católica del Maule, Escuela de Sociología, \\ Centro de Estudios Urbano-Territoriales, Chile \\ julien.vanhulst@gmail.com \\ Cristóbal Rojas \\ Universidad de Concepción, Departamento de Sociología, \\ crojas.alday@gmail.com
}

Peasant raw cheese production in the Arauco Gulf: retro-innovative processes towards socio-ecologically

\section{Resumen:}

Con métodos cualititativos analizamos los procesos de resistencia y (retro) innovación construidos y defendidos por una comunidad de productores de quesos crudos en el Golfo de Arauco (Chile); territorio marcado por el monocultivo forestal. Su existencia y viabilidad económica, desafía la industria forestal y el marco regulatorio existente, particularmente las normas higienistas de pausterización. Confirmamos la hipótesis que el pastoreo local y la producción de quesos con base en leche cruda involucran conocimientos y prácticas antiguas y nuevas, permite la reproducción socioecológica territorial, y responde a la complejidad temporal de las economías campesinas, articulando una red de productores, intermediarios y consumidores.

Palabras ClaVE: Regímenes sociotécnicos, Economía campesina, Ecología política, Resistencia, Mundos relacionales, Chile.

\section{AbSTRACT:}

Using qualitative methods we analyze the processes of resistance and (retro) innovation built and defended by a community of raw cheese producers in the Gulf of Arauco (Chile); a territory marked by the monoculture forestry. Its existence and economic viability, challenges the forestry industry and the existing regulatory framework, particularly the hygienist norms of pausterization. We confirm the hypothesis that grazing and raw milk cheese production involve old and new knowledge and practices, allows territorial socioecological reproduction, and responds to the temporal complexity of peasant economies, articulating a network of producers, intermediaries and consumers.

KEYWORDS: Sociotechnical regimes, Peasant economy, Political ecology, Resistance, Relational worlds, Chile.

\section{INTRODUCCIÓN}

Este artículo busca comprender los procesos retroinnovadores de una comunidad campesina de productores queseros del centro-sur de Chile -sus prácticas, arreglos socioecológicos, y saberes-, que resisten, cuestionan, pero también dialogan con el régimen sociotécnico dominante, marcado por los principios de la economía de mercado capitalista. 
Su sola pervivencia representa una resistencia activa a la trayectoria dominante de la agricultura chilena, que ha seguido un modelo de desarrollo rural, hegemonizado por los agronegocios y la silvicultura intensiva, que naturaliza la racionalidad económica capitalista y sus formas particulares de entender el mercado y las empresas (Gwynne, 2003). Sin embargo, las economías campesinas no se han adaptado completamente a estas reglas (Kay, 2002; van der Ploeg \& Ventura, 2014; van der Ploeg, Ye, \& Schneider, 2015). Por el contrario, han configurado modos de producción híbridos, que conforman potenciales nichos sociotécnicos retroinnovadores, estimulados por el renovado interés hacia una agricultura sustentable. En este sentido, consideramos que las prácticas campesinas locales pueden contribuir a procesos globales de transición hacia la sustentabilidad socioecológica, y tensionar las trayectorias insustentables dominantes.

Aquí describimos la historia y los procesos de producción de quesos artesanales en el Golfo de Arauco, a partir del análisis del nicho de (retro-)innovación sociotécnica configurado por las prácticas, saberes, reglas y relaciones de las comunidades campesinas. El territorio del Golfo de Arauco es arquetípico de los procesos de instalación del régimen sociotécnico extractivista chileno, dado que ha devenido en corazón del modelo de monocultivos forestales (Montalba y Carrasco, 2003). A pesar de ello, permanece un conjunto de familias productoras de quesos de leche cruda que abastece la demanda de ferias y mercados locales. Sus zonas de pastoreo corresponden a las pocas praderas, vegas y humedales que no han sido aún ocupadas por plantaciones forestales. Su presencia y viabilidad económica representan un desafío tanto a la lógica territorial homogeneizadora de la silvicultura industrial como al marco regulatorio existente, cuyas normas sanitarias son incompatibles con la producción tradicional. En este contexto, por una parte, la crianza de vacunos ha permitido a familias campesinas conservar y cuidar sus tierras, que de lo contrario habrían sido vendidas o forestadas; por otra parte, la porfiada producción de quesos de leche cruda, pese al control de fiscalizadores, se ajusta a la complejidad temporal y diversidad productiva de economías campesinas en su búsqueda por autonomía. Todo ello ocurre mientras se produce un queso de organoléptica especial, muy apreciado en los mercados locales.

El documento reflexiona en torno a las tensiones entre el régimen sociotécnico de la economía de mercado en Chile y las prácticas productivas tradicionales locales. Buscamos reconocer al conjunto de familias productoras artesanales de quesos de leche cruda, las cuales desde su posición de ilegalidad han cuidado un nicho sociotécnico propio que articula prácticas productivas patrimoniales, subsistencia de las familias, y preservación de ecosistemas de humedales costeros. Creemos que es necesario cuidar y fortalecer este ensamblaje, a partir de repensar algunas exigencias regulatorias y de revalorización. En consecuencia, nos acercamos al caso a partir de la pregunta sobre la capacidad de adaptación sociotécnica local para dar respuesta a problemas socioambientales contemporáneos, particularmente la valoración del territorio y la búsqueda de autonomía de economías campesinas. Sostenemos que la organización productiva del queso de Arauco constituye un nicho sociotécnico retroinnovador que dialoga y negocia entre definiciones sociotécnicas externas y sus propias definiciones territoriales.

Para ello, proponemos articular teorías generalmente separadas: por un lado, la teoría de la transición (i.a. Berkhout, Smith, \& Stirling, 2004; Geels, 2004), que nos permite entender las prácticas productivas como arreglos sociotécnicos, es decir, un conjunto de normas y prácticas semicoherentes materializadas por los agentes locales; por otro lado, herramientas de la ecología política, más particularmente la idea de construcción socionatural (Escobar, 1996; Latour, 1991; Leff, 2004, 2012), y, finalmente, la sociología rural, particularmente los trabajos que han analizado las economías campesinas y sus relaciones con las dinámicas de desarrollo dominantes. De tal modo, hemos podido relevar cómo la producción local de quesos artesanales en el Golfo de Arauco constituye un nicho sociotécnico retroinnovador (es decir, en simultánea continuidad y ruptura con modos de producción históricos) en el que intervienen actores humanos y no-humanos, y que mantiene/defiende el modo de vida campesino (Chayanov, 1975; Scott, 1985, 1990, 2009; Van der Ploeg, 2010). 


\section{BREVE DESCRIPCión DEL CASO}

El Golfo de Arauco está localizado en el centro sur de Chile, con una topografía costera y montañosa, y una pluviometría bastante alta que llega a $3.000 \mathrm{~mm}$ anual. Ello configura un paisaje de montañas bajas y costa, tradicionalmente de bosque templado lluvioso con lagos, lagunas y humedales. Durante el siglo XX el sector tuvo un desarrollo asociado a la minería del carbón, que coexistía con un entorno campesino. En los últimos 40 años la industria de monocultivos forestales se impuso como la actividad productiva dominante, y ocupó gran parte de las zonas de montaña y parte de la zona de humedales. En el año 2007 (último censo agrario), existían 810 predios forestales dedicados al monocultivo silvícola, lo que constituye 201.987 hectáreas plantadas, correspondientes con el $37 \%$ de la superficie total de la provincia de Arauco, que es una unidad administrativa que en su mayoría se superpone con el Golfo de Arauco. Se estima que en los años siguientes ese porcentaje se ha incrementado.

La producción de queso en Chile se remonta a la época colonial; el uso de leche cruda caracteriza la forma tradicional de producir el "queso chanco", único queso con denominación de origen chilena, cuya elaboración tradicional está en desuso (Lacoste et al. 2015). Actualmente, la ganadería lechera se dispersa en predios pequeños y medianos en el centro y sur de Chile, sin embargo, el $80 \%$ del procesamiento lechero se concentra en cuatro grandes empresas: dos transnacionales (Nestlé y Fonterra) y dos nacionales (Soprole y Colun). En su conjunto, el sector lácteo carece de apoyo o protección estatal en un contexto de economía muy abierta (FEDELECHE, 2015). Por lo tanto, los precios son muy volátiles, lo que afecta principalmente a las pequeñas lecherías.

Es difícil tener una medida precisa del número de productores de queso artesanal en el Golfo de Arauco, debido al carácter ilegal y clandestino de la actividad. Sin embargo, es posible estimar un número aproximado basado en los datos del Censo Agrario 2007 de la Provincia de Arauco. Dicho censo registra 5.523 parcelas agrarias en la provincial que cubren 151.401 ha; $55 \%$ de ellas corresponde a predios de menos de 10 hectáreas, propiedad de campesinos y pequeños agricultores. La mayoría de los predios agrícolas (72\%) tienen ganado bovino con un promedio de 14 animales por granja ( 57.883 animales en total). Debido a la ausencia de elaboradores lácteos grandes en el área, capaces de comprar la producción de leche, es posible suponer que la mayoría de los agricultores producen queso para el consumo interno o para el pequeño comercio.

El caso analizado corresponde así a un estimado de 4.000 unidades familiares campesinas multirubristas. Todos los predios que visitamos eran pequeños, y llevaban a cabo una economía diversa que combinaba la producción de papa o cereales, huertos y pequeñas crianzas de aves de corral, y, a veces, una pequeña piara de cerdos. Son familias pequeñas - de hasta 5 miembros- mayoritariamente envejecidas. Pese a ello organizan su unidad productiva movilizando principalmente el propio trabajo familiar. Poseen predios de hasta 10 hectáreas, muchos de ellos provenientes del proceso de reforma agraria de los años 60 y 70 . El tamaño promedio de la manada de bovinos es de 10 animales por familia, y la fabricación de quesos es la principal, si no la única, fuente de ingresos monetarios para las familias, lo que se complementa en algunos casos con el acceso a pensiones o trabajos remunerados ocasionales. La producción de quesos es histórica y arraigada en el territorio (incluso proveniente de la organización hacendal de principios del siglo XX). Actualmente la cría de animales es principalmente una actividad masculina, pero el ordeño y la fabricación de queso son principalmente actividades femeninas, aunque existen algunos maestros queseros.

\section{Marco teórico y Metodológico}

El presente estudio se apoya en los resultados de una investigación empírica realizada durante los años 2016 y 2017 en el marco del proyecto Cartografías de Heterogeneidad Económica en las regiones del Biobio, Maule y Valparaiso (Fondecyt 1160186), cuyo propósito es reconocer, visibilizar y potenciar la heterogeneidad socio-ecológica de economías comunitarias. 
Desde un enfoque cualitativo se documentó la experiencia de 12 productoras a través de etnografía, instrumentos participativos y entrevistas. El universo analizado corresponde a la comunidad productora del queso artesanal de leche cruda, particularmente maestros/as queseros/as. El carácter ilegal de la actividad y las dificultades de conectividad complejizaron la recolección de información. El proceso de investigación comenzó con dos líderes locales, a partir de los cuales se contactó a otras maestras comercialmente activas, y a dos maestras queseras antiguas portadoras de una memoria de la actividad. Con ellos se hace un recorrido histórico del producto y un análisis de la cadena de valor del mismo, y de su relación con otros actores sociomateriales del territorio, para así reconstruir el arreglo sociotécnico.

La tensión y diálogo entre el contexto estructural -el modelo forestal y el marco regulatorio sanitario nacional-y la agencia de actores locales fue expresada en términos de régimen y nicho sociotécnicos (Geels, 2004), lo que permite una comprensión multinivel de la agencia. Así mismo miramos el territorio y sus procesos, a partir de algunas herramientas teórico-conceptuales de la ecología política, la sociología rural y las teorías de la transición, en particular, las categorías de coconstrucción socionatural y el análisis de economías campesinas.

\subsection{Nicho y régimen sociotécnicos}

Desde la primera mitad del siglo XX la tendencia global y nacional en la producción quesera ha buscado la industrialización y estandarización de procesos sanitarios inocuos, con la homogeneización de las materias primas, calidades gustativas y protocolos técnicos (Du Puis, 2002). Sin embargo, observamos que los productores locales movilizan otros saberes, recursos, redes y cadenas de comercialización para desarrollar modos de producción contrahegemónicos. Estas prácticas construyen "nichos sociotécnicos" insertados en un "régimen sociotécnico" (Berkhout, Smith, \& Stirling, 2004; Geels, 2004). Los "regímenes sociotécnicos" son conjuntos de reglas semicoherentes que organizan actores vinculados a diferentes regímenes metacoordinados (tecnología, ciencia, mercado, sociocultural, política), los cuales guían todo el complejo de prácticas asociadas a la tecnología y a la infraestructura. Su nivel más amplio es el "paisaje sociotécnico", que forma su entorno exógeno, patrones culturales profundos y desarrollos macropolíticos, un modelo sedimentado y estabilizado. A un nivel micro coexisten diferentes nichos sociotécnicos más o menos compatibles con el paisaje y los regímenes sociotécnicos.

Esta aproximación permite concebir formas híbridas de conocimiento y prácticas, y abrir una mirada pluralista sobre los modos de producción y sus relaciones con el entorno natural (Vanhulst \& Beling, 2013a, 2013b). Aquí observamos el encuentro de distintos cuerpos de saber, en armonía y tensión que se materializan en una serie de prácticas interconectadas en torno a la tecnología, las representaciones simbólicas, el trabajo, la naturaleza, la organización, el tiempo, el conocimiento y las estrategias económicas. Estas redefiniciones mezclan antiguos saberes con elementos nuevos en una suerte de "retroinnovación" (Stuiver, 2006) sustentada por actores, que buscan mantener una cierta autonomía y reterritorializar sus modos de vida, movilizando diversas competencias y recursos en un proceso de aprendizaje/adaptación permanente (Agrawal, 1995; Gupta, 1998). Las tensiones entre el nicho sociotécnico local y el régimen sociotécnico dominante se expresa en los modos de concebir las relaciones entre lo social y lo natural, y la lucha por la autonomía propia de las economías campesinas.

\section{2. "Mundos relacionales" y economías campesinas}

La relación entre la producción de queso y el socioterritorio que la alberga se comprende bien desde el lenguaje de la simetría y la coconstrucción (Escobar, 1996; Latour, 1991; Leff, 2004, 2012). Esta visión comprende la interdependencia entre lo social, lo natural y lo tecnológico, como complejas interrelaciones 
de acción, a priori simétricas, que forman redes, ensamblajes y asociaciones heterogéneas que actúan colectivamente y constituyen el mundo que habitamos: un actor red (Callon \& Law, 1997; Murdoch, 2001; Latour, 2004 y Latour, 2006). Ello convoca a trascender la dualidad entre las ciencias naturales y sociales para analizar procesos complejos. También implica la politización de los objetos y la naturaleza, los sujetos llegan al mundo político no solo como individuos lingüísticos, sino como miembros de asociaciones colectivas humanas y no humanas actuantes, que trascienden las dicotomías de sujeto-objeto. Caben entonces en el análisis del tejido de lo real tanto elementos materiales -suelo, semillas, animales, clima-, como inmateriales, tales como las emociones y sentimientos, lo que rompe las separaciones fundamentales del régimen moderno de verdad (Latour, 1991). De esta manera, naturaleza y cultura no aparecen en oposición binaria, y tampoco se asume la existencia de una sola naturaleza. Por el contrario se asumen diversas socionaturalezas -incluso diversas ontologías, esto es, distintas formas de existir- que conectan actores y procesos en agencias distribuidas y relacionales (Escobar, 2016). Desde esta visión, las cosas y los seres son sus relaciones. Escobar (2016), por ejemplo, describe un manglar como la enacción coordinada de un entramado de formas orgánicas e inorgánicas. Este principio de conexión es ilustrado por el autor usando el término budista de interser, donde nada existe en forma autocontenida. Para el autor, la subsunción de los mundos relacionales -que se comprenden desde otras epistemologías y ontologías- bajo modelos homogeneizadores y simplificadores, como el complejo agroforestal, representa no solo un ejercicio de dominación sino de "captura ontológica", que homogeneiza la diversidad y construye "un mundo hecho de un solo mundo". Por el contrario: "La ontología política afirma la importancia de realzar y potenciar el pluriverso y está en contra de la tendencia dominante de representar al mundo como si fuese uno solo" (Escobar, 2016, p. 85).

Frente al régimen sociotécnico dominante podemos observar espacios que dan cuenta de esta realidad pluriversal. Muchas economías campesinas actualmente existentes - con sus propias racionalidades y prácticas- son ejercicios de diferenciación ontológica, de diversidad económica con otras lógicas, prácticas y relacionalidades económicas. Chayanov (1975), en los albores del siglo XX, las describió como espacios heterogéneos subordinados a las necesidades del ciclo familiar, y capaces de organizar los recursos socioecológicos para asegurar su sobrevivencia autónoma. Para los enfoques modernizantes y desarrollistas, estas prácticas se presentan "relegadas a lugares remotos en la historia y en la periferia" (Van der Ploeg, 2010, p. 39). Para otros autores representan prácticas contemporáneas que han sido clave para la sobrevivencia adaptación y flexibilidad- del campesinado (Van der Ploeg, 2010). Para nosotros representan un espacio de diferencia que contribuye a la mantención de ontologías y mundos relacionales.

Van der Ploeg (2010) ofrece una definición comprensiva de la condición campesina centrada en la autonomía -flexibilidad, movilidad, libertad, e independencia respecto a relaciones de explotación y sumisión- y la coproducción ser humano naturaleza, esto es interacción, intercambio y transformación mutua. Así, el proceso de producción se entiende como una totalidad capaz de crear, recrear y mejorar los recursos naturales y sociales, cuidando y ampliando el patrimonio natural, genético y cultural en que se desarrolla. Para el autor, el modo de producción campesinaunifica los factores productivos -trabajo, tierra y capital- en manos del campesino, que los organiza para la salvaguarda y ampliación de su autonomía. El íntimo conocimiento socioecológico del territorio y el aprovechamiento intensivo de los recursos permite ofrecer rendimientos mejores a la agricultura de gran escala, a partir de estrategias tales como pluriactividad (Barkin, 2006), cooperación y reciprocidad, evaluación crítica y desconfiada de innovaciones y prácticas, flexibilidad, y control de riegos, entre otros (Van der Ploeg, 2010). Estas estrategias reconocen la interdependencia con la naturaleza, y representan un espacio para el "pluriverso" o la "ontología relacional" que describe Escobar.

Este objetivo de autonomía aparece en tensión con el modelo de desarrollo de monocultivos. Si bien las economías campesinas deben relacionarse con la economía formal para acceder a los recursos monetarios, también están amenazadas por procesos de "apropiacionismo” y “sustitucionismo” (Goodman et al., 1987). Desde esta perspectiva, los procesos de despoblamiento y recampesinado pueden verse como una pérdida 
frente a la articulación y reconstrucción activa de los procesos de reproducción socionatural autónoma. El tema de la autonomía contiene, pues, una dimensión política de resistencias no necesariamente abiertas, sino de carácter cotidiano, lo que Scott (1990) llama los "puntos fríos" de resistencia, por oposición a la rebelión y a la resistencia abierta. El trabajo de $\operatorname{Scott}(1985 ; 1990 ; 2009)$ ha profundizado en las diversas armas políticas -e infrapolíticas- que el mundo campesino moviliza para mantener su propio discurso contra la dominación. La ilegalidad de la actividad económica analizada en este artículo refleja la tensión histórica entre las comunidades rurales fugitivas, que mantienen prácticas deliberadas de ocultamiento y evasión contra el Estado para mantener su autonomía económica y política (Scott, 2009). Por lo tanto, la negativa a pasteurizar se puede ver como el mantenimiento obstinado de la autonomía productiva, y también como un grupo de espacios periféricos que resisten los intentos centrales de integración, regulación y monetización, para lograr la "rentabilidad" y la auditabilidad, desde una perspectiva nacional. Scott (2009) describe cómo las comunidades desarrollan estrategias de adaptación para evadir el control, por ejemplo, ubicándose en tierras con bajo valor agrícola, que se convierten en áreas de refugio para economías y formas de vida campesinas. Esto no significa, sin embargo, que sean comunidades aisladas. A medida que el capitalismo dominante se expande, se producen nuevos "encierros", por lo que estas tierras adquieren valor. Este es el caso, por ejemplo, de la industria forestal, que se ha ubicado en tierras de bajo valor. Por lo tanto, estas economías deben entenderse en relaciones recíprocas, contemporáneas y de resistencia infrapolítica con el régimen sociotécnico dominante.

\section{ANÁlisis DE LOS RESUltados}

\subsection{El régimen sociotécnico: modelo forestal exportador e higienización de la producción alimentaria}

La vida de las comunidades productoras de queso se enmarca en un escenario de macrotensión entre distintos mundos ontológicos: por una parte, la homogeneización territorial guiada por un régimen sociotécnico agroexportador convencional, desterritorializado e higienista, y, por otra parte, procesos de búsqueda deautonomía económica por parte del mundo campesino e indígena que defiende no solo el derecho a permanecer y vivir bien en sus tierras, sino también sus saberes y procesos de subjetivación. Contextualizaremos el régimen sociotécnico agroexportador a través de dos de sus expresiones: el desarrollo de la industria forestal que desplaza territorialmente a la agricultura campesina y el higienismo agroalimentario que, buscando la estandarización, criminaliza y marginaliza las prácticas de producción alimentaria tradicionales. Entre ambos, constituyen un ejercicio que aniquila otros modos de vivir.

La industria forestal ha experimentado un explosivo crecimiento, y ha alcanzado, en el año 2014, un valor de US\$ 6.094,3 FOB en exportaciones forestales totales, ${ }^{1}$ con un apoyo activo del Estado. Primero, se benefició de los procesos de contrarreforma agraria, liberalización de la economía, represión del movimiento sindical y flexibilización del mercado del trabajo, desarrollados durante la dictadura militar (Gwynne, 1993). Posteriormente, se nutrió de una política de promoción forestal, particularmente el Decreto con Fuerza de Ley DL701 (1974), que subsidió hasta $75 \%$ de los costos de producción. Éste, originalmente vigente hasta 1998, fue ampliado hasta el año 2011, y entregó beneficios especiales a pequeños y medianos propietarios (Leyton, 2009), por lo que se convoca a los pequeños propietarios como aliados del negocio forestal. Esto implica una profunda transformación de la agroecología del territorio por la colonización de monocultivos forestales demandantes de recursos hídricos, amplio uso agroquímicos y en permanente riesgo de incendios (Cid, 2015). Ello es acompañado por una transformación de los modos productivos de las economías campesinas. Si éstas se organizan en torno a los ciclos agrícolas y familiares, la plantación forestal no ofrece ganancias periódicas, lo que obliga a la asalarización. 
Un segundo elemento gravitante en el territorio es el ejercicio de higienismo que estandariza las prácticas tradicionales. La pausterización es central en las ontologías modernas como ejercicio de racionalización: a través de la eliminación de microorganismos, seres con su propia e ingobernable agencia, se buscó controlar el conjunto relaciones sociomateriales en torno a una variedad de actividades, desde la fermentación hasta a la cirugía. Así, se erradican "millones de otros individuos, moviéndose alrededor, que no podemos ver" (Latour, 1993, p. 35), de tal manera de hacer posible "[para] obtener relaciones que nada desviará" (Latour, 1993, p. 39), esto es, incrementar la controlabilidad sobre el proceso. La pasteurización ha sido un dispositivo sanitario y económico central en la industria láctea (DuPuis, 2002). La escala de la producción lechera industrial -que involucra confinamiento de animales, volúmenes de producción elevados, y dispersión espacio temporal- hace necesaria la pasteurización para asegurar la inocuidad. Sin embargo, desde los movimientos de relocalización alimentaria, su obligatoriedad ha sido objeto de cuestionamiento. En ese contexto, eliminar la flora bacteriana original obliga a la adición de fermentos lácteos industrializados que homogeneizan la producción quesera, limitando con ello en anclaje territorial de artesanías alimentarias (Frog, 2006, citado en Grass y Cesín, 2014, p. 203). Desde el año 1930, el Estado chileno hace obligatoria la pasteurización, salvo localidades expresamente exentas (Ley No 4869, Artículo 200). Dicha ley buscó estandarizar procesos industriales y sanitarios inocuos para una agroindustria moderna, ajustada a protocolos técnicos parametrizados. A partir de la misma, las formas tradicionales de hacer queso han sido criminalizadas.

En suma, el régimen sociotécnico hegemónico de Nahuelbuta responde al imperativo del crecimiento económico con un modelo de desarrollo silvoagroexportador industrializado, pero también a un marco regulatorio que busca asegurar la inocuidad sanitaria, basado en una visión tecnocientífica uniformizada. En su conjunto desplazan y homogeneizan las economías campesinas en un proyecto de intensa transformación del territorio.

\subsection{La quesería tradicional como nicho sociotécnico retroinnovador}

La lechería y quesería tradicional, creemos, constituye un nicho sociotécnico relacional donde cohabitan (Interson) campesinos, humedales, pasto, vacas, bacterias, etc., en un entramado cuya viabilidad económica ha sido capaz de mantenerse frente a la expansión territorial homogeneizadora de la industria forestal. Representa otros repertorios, y otras maneras de concebir las economías locales que se oponen a esta despersonalización de los intercambios, la uniformización de los productos y la homogeneización del territorio. La suerte misma de los ecosistemas locales está íntimamente asociada a este nicho, pues los humedales aún no han sido transformados en monocultivos forestales, gracias a su uso para pastoreo. La producción tradicional de leche cruda constituye una danza en que participan multiplicidad de actores entre ellos muchísimos que no podemos ver- y que forman parte del entramado de relaciones que rodea a sus actores visibles. En esta danza, sus cultores -las maestras y los maestros queseros- deben ser verdaderos coreógrafos que siguen complejos rituales para asegurar que cada danzante colabore en el proceso. Por el contrario, la quesería moderna aniquila a muchos de los danzantes invisibles, simplifica y hace más controlable el proceso, y deriva luego en productos estandarizados que no portan en sí la complejidad sociomaterial de su territorio.

En este apartado nos detendremos en tres momentos. Primero, la relación entre quesería tradicional, como práctica económica viable, y la reproducción socioecológica ampliada del territorio. Posteriormente, haremos un análisis de cómo la temporalidad de la producción lechera en queso crudo se ajusta a la diversidad productiva campesina. Para terminar este apartado, discutiremos la forma como las familias camuflan la ilegalidad del proceso. 


\subsection{Queserías y la reproducción socioecológica del territorio}

La quesería tradicional familiar es una práctica productiva y ecológica fuertemente amarrada a la morfología del territorio. Los relatos de maestras queseras antiguas remontan su práctica a las economías hacendales, en las que se producían quesos para comercialización y consumo doméstico, usando cuajos naturales provenientes de rumen vacuno. Con la reforma agraria, esta práctica se habría trasladado a las economías campesinas, lo que permitió, como veremos, su sostenibilidad económica y socioambiental. La permanencia de esta actividad descansa en la transferencia intergeneracional de saberes prácticos y repertorios productivos: "Y ella [la abuela] enseñando todo, 'esto van a hacer ustedes cuando sean grandes', decía, ‘aprendan!’” (Maestra quesera, 2016).

A diferencia de diseños más industriales, que deslocalizan el proceso, la quesería familiar integra el mismo en la organización predial, incluyendo la crianza de ganado en pradera abierta -vegas y humedales naturales-, la ordeña y posteriormente la elaboración del queso. Hacer quesos no es una actividad exclusiva, sino parte de la diversidad económica campesina, que coexiste con la producción cerealera, huertería y recolección. La quesería es, sin embargo, una actividad muy central para las familias, pues generalmente constituye la principal, sino la única, fuente de ingresos monetarios.

La crianza de ganado no estabulado está vinculada a la existencia de los humedales costeros de Arauco. Cada maestra quesera posee "hijuelas" dotadas de praderas naturales que fluctúan entre las 10 y las 20 hectáreas. Son terrenos de baja calidad agrícola, pero con alta densidad ecológica, compuestos de humedales y salinas, que son lugares de nidificación de aves y asentamiento de fauna menor. Su bajo valor agrícola y comercial los hace objetivo privilegiado de la industria forestal; así, el uso económico que la lechería hace de estos humedales es quizás lo único que ha permitido su conservación. La alimentación del ganado en pradera abierta es al mismo tiempo relevante tanto para la producción quesera como para la sostenibilidad ambiental de la actividad. El cuidado de las vegas determina la cantidad y calidad de la leche y también la organoléptica del queso. Asimismo, la pastura en vegas representa un uso respetuoso del territorio, al producir un agroecosistema que sustenta a la comunidad quesera a la vez que mantiene humedales -ecológicamente diversos- como alternativa rentable frente al monocultivo forestal.

\subsection{Leche cruda y economías campesinas: el valor del tiempo para una economía diversa}

Luego de la ordeña, el queso es elaborado en pequeñas queserías, consistentes en una pieza de madera dotada de bateas, moldes y zarandas. La receta tradicional de queso usaba como cuajo la manzanilla, que es un fermento casero elaborado a partir del rumen vacuno y hierbas locales. Ésta, dado su $\mathrm{pH}$ ácido, cuaja la leche, pero es también rica en bacterias -fuertemente territorializadas- que permiten la fermentación y maduración del queso. El uso de la manzanilla involucraba un procesamiento tradicional: "Se enfuertaba ligerito, ¿ni que la manzanilla es ojúa?, rica pa' hacer suero: con un pedacito había pa’ echarle al cántaro. Después yo la sacaba esa, la lavaba con el mismo suero, la salaba y la colgaba al humito" (Maestra antigua, 2016).

Esta práctica es desconocida para las queseras jóvenes, que aprendieron el oficio después de la masificación del cuajo sintético. Las prácticas tradicionales del uso de leche cruda y rumen de vacuno entran en conflicto con las políticas de inocuidad alimentaria, que desde 1930 sancionan la pasteurización obligatoria, y desde 1960 la prohibición de faenar animales fuera de mataderos autorizados, lo que limita la obtención de rumen. Estas medidas han relegado las prácticas tradicionales de producción de queso a la ilegalidad, ante lo cual muchas familias han optado por reemplazar la manzanilla por cuajo sintético. Sin embargo, han sido muy resistentes frente a la pasteurización. En esta sección queremos explorar la causa de esta porfiada resistencia, que se relaciona con la complejidad del proceso económico ampliado y la búsqueda de autonomía campesina, 
y que las ha llevado a negociar entre repertorios sociotécnicos modernos y tradicionales, adaptando y adoptando en forma selectiva, distintos protocolos.

La manufactura del producto comienza con la ordeña manual ejecutada en pequeños establos, e involucra el lavado sistemático de las ubres y acopio de la leche en modernos baldes de acero. Posteriormente, la leche es trasladada a la quesería, momento en el cual debería ser pasteurizada. Sin embargo, los productores consideran el uso de leche cruda como elemento diferenciador: "porque el queso artesanal de verdad es crudo" (Maestra, julio de 2016). La leche es cortada con cuajo, principalmente sintético; luego es lavada -para remover el suero- y depositada en una batea de acero inoxidable donde decanta el suero para luego añadirle sal y amasar. La masa es amoldada y prensada por horas utilizando materiales de acero inoxidable (doberas, zunchos y tinetas) como demandan los repertorios modernos. El uso selectivo de prácticas modernas es considerado como un avance en higiene: "La tabla de antes es como más llamativa a las bacterias y lo de ahora no, ahora es más limpio" (Maestra quesera, 2016).El proceso de maduración es limitado; se vende el queso en fresco. Esto se debe a dos razones. Primero, el carácter ilegal del producto, que lleva a los queseros a evitar almacenar mercancía en sus bodegas, y segundo, al reemplazo de los cuajos y fermentos tradicionales por cuajo sintético, que carece de la flora bacteriana necesaria para una maduración extendida.

Ahora bien, si el proceso de pasteurización -legalmente obligatorio- podría compensar ciertas lasitudes higiénicas en el proceso, pues elimina microbios y reduce su capacidad de desarrollo posterior, el trabajo con leche cruda invoca importantes cautelas higiénicas. Así la opción por la leche cruda, un material biológico delicado y riesgoso, involucra un conjunto de prácticas y criterios sociotécnicos compartidos tradicionales y modernos- que constituyen verdaderos estándares de calidad local. Para ello las productoras hacen un seguimiento riguroso del calendario de vacunación y cuidados veterinarios. Asimismo, asumen varias recomendaciones del código sanitario moderno: superficies y materiales lavables, vestimentas especiales y lavado de manos. Junto a ello, mantienen procedimientos tradicionales como el baño -no solo lavado de manos sino del cuerpo completo- antes de amasar, el uso de cenizas para desinfectar, y el lavado y amasado de la cuajada para remover restos de suero y cuajo. La falta de cumplimiento de estas prácticas arriesga la calidad del queso: "Hay algunos quesos que uno ve como que están desparramados y con hoyitos, eso es porque no está bien lavada la cuajada"; "Si usted la lava con poca agua el queso se pone baboso encima" (Maestras queseras, 2016). Asimismo, estas prácticas muestran el carácter manual de un proceso que exige a sus cultores compromiso físico y temporal con el mismo.

...el queso queda firme y da gusto llenar un canasto de queso (...) Si uno deja la cuaja' ahí nomás a que estile sola, que no la mueve y la deja ahí en el paño, entonces la cuaja' se avinagra y eso es una cochina', (...) se vuelve una mazamorra" (Maestra quesera, 2016).

Aspectos como la buena palatabilidad de los quesos crudos y su menor precio han mantenido su demanda, lo que ha incentivado su producción a pesar de su ilegalidad. No obstante, creemos que existen razones más profundas que explican la resiliencia de la actividad. Éstas remiten a la estructura de uso de tiempo de economías campesinas, diversas y pobladas de heterogeneidad de actores y prácticas económicas. Pasteurizar demanda una supervigilancia constante -controlar temperatura y revolver-como también un tiempo de cuajada significativamente mayor, que consume el tiempo normalmente destinado a otras actividades:

...si le saco la leche a las 9, a las 10 está la leche cortada; y yo saco "al tiro" y hago "al tiro" el queso. Y el queso pasteurizado no, porque yo tenía que calentar la leche ahí todo el rato y estar ahí, viendo pos’; después ir, sacarla y moverla rápido porque si no se ponía dura, como cocida. ¡Así no! ¡Así no me gustó! (Maestra quesera, 2016).

De esta manera, pausteurizar limitaría la posibilidad de mantener la diversidad productiva de las economías campesinas, donde efectivamente la quesería es solo parte de un modo de subsistencia ampliado. Además, la pasteurización limita las posibilidades de comercialización inmediata, dada la organoléptica del queso fresco:

Tiene que esperar los 8 días de maduración para poder venderlo, en cambio el de acá no: usted lo hace hoy y ya mañana lo puede vender; la gente se lo puede servir "al tiro", en cambio el pasteurizado no (...) es como chicle (Maestra quesera, 2016). 
En suma, la quesería con leche cruda permite un uso del tiempo que es sensible a las complejidades y repertorio diverso de las economías campesinas, y asegura una entrada constante de dinero sin comprometer las otras actividades productivas; esto asegura la subsistencia familiarampliada (van der Ploeg, 2009, en Landini, 2011:10). Y ello se encuentra luego redinamizado por "la creciente importancia concedida a los productos 'localizados” (Bérard y Marchenay, 1996, p. 32), por la cual la economía campesina logra encontrar un nicho de trabajo en la creciente demanda por artesanías alimentaria.

\subsection{Regulación estatal y economía del camuflaje}

Las familias productoras de quesos de leche cruda tienen una relación ambivalente con el Estado. Por una parte, gran parte de ellas ha recibido alguna forma de subsidio para la construcción de corrales y queserías; por la otra, el producto de las queserías es manifiestamente ilegal bajo el ojo regulatorio. Las maestras queseras hablan de "olas de allanamientos" y decomisos policiales que terminan con la destrucción de productos. En palabras de una maestra quesera: "se los quitaban nomás y los botaban, se los daban a los perros. Pobre gente que iba a vender sus quesos" (Maestra antigua, 2016). Frente a ello se despliegan diversas prácticas de encubrimiento. Por ejemplo, cuando se las fiscaliza, las queseras niegan la actividad, lo que se verifica por la ausencia de quesos almacenados: "Cuando venían aquí a hacer las cosas, nosotros les decíamos que ¡no hacíamos na’ queso!” (Maestro quesero, 2016).La informalidad resguarba así la actividad, pues el personal sanitario solo tiene listadas las queserías regularizadas.

Así, se evita también la venta directa al público para evitar visibilizar la actividad: "La gente venía a preguntarle: ‘¿usted hace queso?’; ‘ino! no hay queso’, y no hay nomás, ¡no importa que tuvieran la quesería llena de quesos! Por el miedo a que apareciera sanidad"(Maestro quesero, 2016). Por el contrario, se comercializa a través de una amplia cadena de intermediarios que compartimentan y obscurecen la trazabilidad para proteger así a las queseras. Para ello, se mantienen relaciones de larga data: "llevo tres años con él trabajando. Y él pasa buscando los quesos (...) dos veces a la semana me retira los quesos" (maestra quesera, 2016). Se mantiene así un acuerdo comercial consuetudinario basado en la confianza, en el no queda registro de la transacción. Éste es reforzado por la circulación de dádivas y favores y por el compromiso de estrictas prácticas de periodicidad, discreción y protección mutua. Adolece, sin embargo, de secretismo en los precios de reventa y desconocimiento de las ganancias de intermediación.

La venta final del queso se realiza en espacios públicos como ferias libres y mercados locales. Allí, pequeños puestos callejeros ofrecen los quesos pasteurizados y legales sobre la mesa de exposición, mientras los quesos crudos se guardan ocultos. Así el queso crudo no está expuesto, pero sí disponible para los conocedores que pregunten por él:

Se escondían cuando pasaba Sanidad, para que no les vieran los quesos artesanales, así que siempre escondido el artesanal. Siempre tienen puestos arriba los pasteurizados nomás. (...) Y la gente ya sabe y les compra los artesanales (Maestra quesera, 2016).

Desde organismos gubernamentales, por su parte, ha habido ejercicios de normalizar la producción quesera a través de asesorías y apoyos materiales. Uno de los esfuerzos más sostenidos fue el apoyo a la constitución de la Cooperativa Campesina Río Carampangue. Desde su creación en 1995, hasta el remate de sus instalaciones en 2014, promovió la colectivización y homologación de los procesos productivos, a través de la compra y pasteurización de leche, y su elaboración en una planta certificada (INDAP, 2013).La comunidad productora explica el fracaso de la Cooperativa por su incompatibilidad con los repertorios productivos y económicos tradicionales. Por una parte, resintieron verse reducidos a ser solo proveedores de leche, lo que redujo sus ingresos: "Querían comprarles la leche después, pero la gente tampoco quiso porque pagaban tan barata la leche” (maestra quesera, 2016). Así también, el proceso productivo era considerado ineficiente, y costoso: 
...era mucho gasto: tenían que comprar el gas, requerían de harto tiempo iy se les iba todo el día en eso! Imagínese que había que calentar la leche, después helarla y dejarla a cierta temperatura nomás, para poder ponerle los cuajos, y de ahí esperar otro tanto a que se cortara (maestro quesero, 2016).

Por último, se culpa a la pobre palatabilidad del producto, que no habría sido capaz de replicar las recetas tradicionales domésticas, cuya organoléptica es demandada por los consumidores locales: “ivendieron uno que otro! y se quedaron con los quesos (...) imalos los quesos, duros! claro, usted los veía amarillitos, pero malos, duros" (maestro quesero, 2016).

En síntesis, el quiebre de la Cooperativa se debería a la inconsistencia entre los repertorios productivos y económicos promovidos por las instituciones del Estado (afirmando el régimen socio-técnico dominante) y los repertorios de fabricantes de queso utilizados tanto en la fabricación doméstica artesanal como en la comercialización del queso de leche cruda del golfo de Arauco (como nicho sociotécnico). Los consumidores también desempeñaron un papel en esta tensión, ya que estaban acostumbrados a la textura suave y al rico sabor del queso crudo, y no aceptaron este nuevo queso, que se parece demasiado al queso industrial.

\section{IMAGINANDO TRANSICIONES: BACTERIAS DE LA MANZANILLA Y NUEVAS POSIBILIDADES DE PRODUCCIÓN SUSTENTABLE}

Si las queseras de Arauco han sido celosas en defender la no pasteurización, no han tenido el mismo celo en mantener la receta tradicional con manzanilla. Este ingrediente -de fabricación doméstica a partir de la fermentación del rumen en suero de leche y hierbas- ha sido ampliamente reemplazado por cuajo sintético. Las antiguas queseras manifiestan su desilusión:

¡Ahora hacen con puro líquido y polvo nomás!, no hacen con suero, no les gusta. Dicen que es un recelo hacer con suero.

(...) Por las manzanillas, ¡es que no lavarán las cosas! (...) les gusta la facilidad primero (Maestra antigua, 2016).

La pérdida del cuajo tradicional tiene consecuencias en la organoléptica del queso y especialmente en su proceso de maduración. El cuajo sintético, si bien consigue un cuajado rápido y eficiente -y que, en combinación con las bacterias de la leche, la ubre y la mano, logra un queso fresco de excelente calidad-, no asegura un buen proceso de maduración largo, dado que el envejecimiento requiere un complejo microbiológico sofisticado, el cual, para la producción industrial se obtiene a partir de cuajos bacterianos específicos. La elaboración de la manzanilla, en combinación con las hierbas locales, producía una combinación de bacterias - fuertemente territorializada- que creaba el sabor especial del queso de Arauco tradicional. Sabor que solo existe ahora en contadas queserías.

Ahora bien, son precisamente esas olvidadas bacterias las que podrían fortalecer -y eventualmente legalizar- el queso de Arauco. En el contexto actual, una de las piedras de toque para la legalización de los quesos de leche cruda es el riesgo de zoonosis. Lo interesante es que las bacterias mueren durante los procesos de maduración larga, por lo que, en quesos muy maduros, la posibilidad de contagio desaparece (Fox, 2004). De esta manera, legalizar los quesos de leche cruda transitaría por recuperar prácticas de maduración, las que, como vimos, están limitadas primero por el uso de cuajos sintéticos y, más importante, por la ilegalidad del producto, que promueve la venta en fresco. Además, desde la perspectiva económica de las comunidades, prácticas de maduración que recojan el carácter y sabor local del producto permitirían constituir un producto para mercado de nicho. Es por ello que es posible pensar en diseños que articulen a organismos regulatorios, expertos en tecnología de alimentos, y a la comunidad local para cultivar el suero manzanilla según su receta antigua y extraer los componentes biológicos del tradicional preparado. De esta manera, la comunidad mantendría un suero biológico - autorizado sanitariamente-, que permitiría la maduración de quesos y, de esa manera, obtener la inocuidad. Ello abriría la posibilidad de recuperar el sabor del queso de Arauco, contribuir a la sostenibilidad económica de las comunidades y mantener una reproducción socioecológica del territorio. 


\section{REFLEXIONES FINALES}

El queso crudo del Golfo de Arauco constituye una producción encastrada en el territorio, sus grupos humanos y ecosistema, que ensambla la práctica quesera, conocimientos locales, el paisaje de humedales costeros, y las bacterias como actores invisibles. La actividad sostiene y recrea una red informal de apoyo, y mantiene un espacio en el mercado, generando ingresos que permiten una buena vida para las familias. Mantienen así un modo de producción relacional y profundamente asociado a la sociodiversidad del territorio, que resiste activamente el proceso de homogeneización socioecológica de la industria forestal, la cual responde al régimen dominante en el territorio. Así, la fabricación de quesos puede ser observada como un nicho sociotécnico local que está en disputa territorial con la industria forestal, a la vez que encapsulado y en negociación con el régimen sociotécnico homogeneizante de la industria quesera y sus sistemas expertos. Debe negociar, aceptar y dialogar con ellos sobre temas como la higiene y la inocuidad.

Creemos que mantener y ampliar este nicho implica al menos tres diálogos. El primero se refiere los marcos regulatorios modernos y las prácticas higiénicas tradicionales. Actualmente, la permanencia de este nicho local de innovación sociotécnica se ve amenazada por las exigencias de los requisitos de salud formales, que no solo fueron diseñados para la producción industrial, sino que tampoco reconocen la alteridad de la economía campesina. Muchos de los estándares sanitarios son de difícil implementación para las empresas familiares, y la pasteurización es difícilmente compatible con la pluriactividad y temporalidad rural. En este contexto, abandonar la fabricación de queso con leche cruda amenaza una forma de subsistencia amplia y sus vínculos con el territorio. En otras palabras, el ejercicio ontológico normalizador de la normativa sanitaria amenaza un nicho productivo que es capaz de mantener una relación simétrica y relacional con su medio ambiente.

Ahora bien, la salud pública es ciertamente un bien colectivo a salvaguardar, especialmente en relación a productos alimentarios de alta circulación local. Creemos que es posible generar dispositivos que medien entre las demandas del Reglamento Sanitario de los Alimentos y las prácticas productivas y socioecológicas territoriales. Los referenciales de calidad deben ser un constructo entre expertos, productores, consumidores y decidores políticos que dialogue entre políticas higienistas y prácticas artesanales de gestión de la calidad y del proceso. De hecho los repertorios sociotécnicos desplegados por las queseras actualmente mezclan elementos de tradición y de modernidad, por lo que coexiste el uso de leche cruda y el amasado manual con el acero o el cuajo sintético; estrategias formales de vínculo con el gobierno a la vez que informales y clandestinas. Se trata de procesos de aprendizaje, adaptación y negociación permanente. Así, vemos que el conocimiento, las reglas, prácticas y estrategias económicas de la comunidad son elementos culturales que no son estáticos (Agrawal, 1995; Gupta, 1998). Son así nichos sociotécnicos plurales que abren la posibilidad de diálogo bidireccional y democrático para un proceso de transición. Al respecto, creemos necesario en principio reconocer y legitimar las buenas prácticas sanitarias desarrolladas por la propia comunidad. Prácticas que ya se adaptan y negocian con la normativa sanitaria formal.

Un segundo diálogo se refiere a otro proceso de aprendizaje potencial: la cooperación entre el conocimiento tradicional en torno al proceso de fermentación, basado en bacterias territorializadas, y la ciencia biotecnológica moderna, capaz de recrear este proceso en el laboratorio y satisfacer los requisitos sanitarios actuales. Este es un desafío amplio para la construcción colectiva de un patrimonio alimentario, que en este caso involucra la revitalización y reinvención de las prácticas de procesamiento del rumen a través de la redomesticación de bacterias territoriales por las nuevas tecnologías. Este diálogo abierto entre el conocimiento local y el conocimiento científico sobre la valoración de un patrimonio colectivo biológico, cultural y territorial podría dar lugar a nuevos regímenes sociotécnicos de carácter retroinnovador, capaces de proponer utopías retroprogresistas. Esto es, dispositivos de las propias actoras para sustentar y mantener una cierta autonomía, como también para reterritorializar sus modos de vida.

Un tercer diálogo implica la participación activa de los consumidores. Actualmente, el queso Arauco tiene una demanda estable en mercados de feria y callejeros en pueblos y ciudades cercanas. Esto sigue siendo 
precario e incapaz de generar suficiente demanda para apoyar a amplias economías campesinas y alcanzar todo el territorio. Creemos que este tipo de queso tiene potencial para acceder a un mercado más amplio, vinculado a las nuevas sensibilidades urbanas sobre los alimentos tradicionales, naturales y del patrimonio. Un mercado ampliado proporcionaría un ingreso más estable a las economías campesinas, mantendría el complejo estilo de vida de las familias locales y haría de la producción de queso crudo una actividad atractiva para las generaciones futuras: un nicho que permite la interacción entre familias, vacas, bacterias y humedales para la preservación y mejora de todos sus actores.

\section{Agradecimientos}

Este trabajo fue apoyado por el FONDECYT-CONICYT bajo el proyecto FONDECYT N ${ }^{\circ} 1160186$.

\section{BiBLIOgRAFÍA}

Agrawal, A. (1995). Dismantling the divide between indigenous and scientific knowledge. Development and change, 26(3), 413-439. https://doi.org/10.1111/j.1467-7660.1995.tb00560.x

Barkin, D. (2006). Reconsiderando las alternativas sociales en México rural: estrategias campesinas e indígenas. Polis, revista de la Universidad Bolivariana, 15. (on line)b Recuperado de: http://polis.revues.org/4982

Bérard, L. y Marchenay, P. (1996). La construcción social de los productos de la tierra. Agricultura y sociedad, 80-81, pp. 31-56.

Berkhout, F., Smith, A. \& Stirling, A. (2004). Socio-technological regimes and transition contexts. In B. Elzen, F. W. Geels \& K. Green. System innovation and the transition to sustainability: theory, evidence and policy, $48-75$. Cheltenham: Edward Elgar Publishing.

Callon, M., y Law, J. (1997). After the individual in society: Lessons on collectivity from science, technology \& society. Canadian journal of sociology, 2(2), 165\#182. DOI: https://10.2307/3341747

Chayanov, A. V. (1975). Sobre la teoría de los sistemas económicos no capitalistas. Cuadernos políticos, 5, 15-31.

Cid-Aguayo, B. (2015). Economías campesinas, industria forestal e incendios: inestabilidad socionatural y la agricultura como resistencia. Ambiente \& sociedade Vol XXIII(1), 99 - 120. DOI: https://10.1590/1809-4422

Du Puis, M. (2002). Nature's perfect food. How milk became America's drink. New York \& Londres: New York University Press.

Escobar, A. (1996). Constructing nature. In R. Peet., Liberation ecologies: environment, development, social movements (pp. 46-68). Abingdon-on-Thames: Routledge.

Escobar, A. (2016). Autonomía y diseño: La realización de lo comunal. Popayán: Universidad del Cauca. Sello Editorial Physics.

FEDELECHE (2015). "Los 15 años de FEDELECHE: La historia del gremio lechero relata por sus protagonistas". Documento de Trabajo.

Fox, P. F, Mcsweeney, P. L. H., Cogan, T. M. \& Guinee, T. O. (2004). Cheese: chemistry, physics and microbiology. Amsterdam: Elsevier Academic Press.

Geels, F. W. (2004). From sectoral systems of innovation to socio-technical systems: Insights about dynamics and change from sociology and institutional theory. Research policy, 33(6), 897-920. DOI: https://10.1016/j.resp ol.2004.01.015

Grass, F.G., y Cesín, A. (2014). Situación actual y retrospectiva de los quesos genuinos de Chiautla de Tapia, México. Agricultura, sociedad y desarrollo, 11(2), 201-221. DOI: https://10.22231/asyd.v11i2.70

Goodman, D., Sorj, B. \& Wilkinson, J. (1987). From Farming to Biotechnology: A Theory of Agro-Industrial Development. Oxford: Basil Blackwell.

Gupta, A. (1998). Postcolonial developments: agriculture in the making of modern India. Durham: Duke University Press. 
Gwynne, R. N. (1993). Non-traditional export growth and economic development: the Chilean forestry sector since 1974. Bulletin of Latin American research, 12, 147-169. DOI: https://10.2307/3338145.

Gwynne, R. N. (2003). Transnational capitalism and local transformation in Chile. Journal for economic and social geography, 94(3), 310-321.DOI: https://10.1111/1467-9663.00259

INDAP. 2013. Productores de quesos actualizan sus conocimientos en dia de campo ganadero: https://www.indap.gob.cl/noticias/detalle/2013/03/26/productores-de-quesos-actualizan-sus-cono cimientos-en-d\%C3\%ADa-de-campo-ganadero

Kay, C. (2002). Chile's neoliberal agrarian transformation and the peasantry. Journal of agrarian change, 2(4), 464-501. DOI: https://doi.org/10.1111/1471-0366.00043

Lacoste, P., Castro A., Jiménez D., Soto N., Rendón, B. \& Briones, F. (2015). The rise and fall of Chanco cheese in Chile (1860-1930). International journal of agriculture and natural ressources 42(1), 85-96.

Landini, F. (2011). Racionalidad económica campesina. Mundo agrario, 12(23). (on line) Recuperado de http:// www.mundoagrario.unlp.edu.ar/article/view/v12n23a14/195

Latour, B. (1991). Nous n'avons jamais été modernes: essai d'anthropologie symétrique. Paris: La Découverte.

Latour, B. (1993). The pasterurization of france. Cambridge, Massachusetts \& London: Harvard University Press.

Latour, B. (2004). Politics of nature: how to bring the sciences into democracy. Cambridge: Harward University Press.

Latour, B. (2006). Reassembling the social. An introduction to actor network theory. Oxford: Oxford University Press.

Leyton, J. I. (2009). Tenencia forestal en Chile. FAO. Recuperado de http://www.fao.org/ forestry/54367/es/chl/

Leff, E. (2004). Racionalidad ambiental: la reapropiación social de la naturaleza. Madrid: Siglo XXI.

Leff, E. (2012). Latin American environmental thinking: a heritage of knowledge for sustainability. Environmental ethics, 34, 331-450. DOI: https://10.5840/enviroethics201234442.

Montalba-Navarro, R., y Carrasco, N. (2003). Modelo forestal chileno y conflicto indígena èecologismo cultural mapuche?. Ecología politica, 26, 63-77. https://dialnet.unirioja.es/servlet/articulo?codigo=1255882

Murdoch, J. (2001). Ecologising sociology: actor-network theory, co-construction and the problem of human exceptionalism. Sociology, 35(1), 111-133. DOI: https://10.1177/0038038501035001008

Scott, J. (1985). Weapons of the Weak: Everyday Forms of Peasant Resistance. New Haven \& Londres: Yale University Press.

Scott, J. (1990). Domination and the Arts of Resistance: Hidden Transcripts. New Haven \& Londres: Yale University Press.

Scott, J. (2009). The art of not being governed. An anarchist history of South East Asia. New Haven \& Londres: Yale University Press.

Stuiver, M. (2006). Highlighting the retro side of innovation and its potential for regime change in agriculture. Between the local and the global, 12, 147-173). Emerald Group Publishing Limited. DOI: https://10.1016/S 1057-1922(06)12007-7

Van Der Ploeg, J. D. \& Ventura, F. (2014). Heterogeneity reconsidered. Current opinion in environmental sustainability, 8 (Supplement C), 23-28. DOI: https://10.1016/j.cosust.2014.07.001

Van Der Ploeg, J. D., Ye, J. \& Schneider, S. (2015). Rural development: actors and practices. Constructing a new framework for rural development, 22, 17-30. DOI: https://10.1108/S1057-192220150000022001

Van Der Ploeg, J. D. (2010). Nuevos campesinos: campesinos e imperios agroalimentarios. Barcelona: Icaria Editorial

Vanhulst, J. \& Beling, A. E. (2013a). Buen vivir et développement durable: rupture ou continuité\#? Ecologie \& politique, 1/2013(46). DOI: https://10.3917/ecopo.046.0041

Vanhulst, j. \& Beling, A. E. (2013b). El buen vivir: una utopía latinoamericana en el campo discursivo global de la sustentabilidad. Polis. Revista Latinoamericana, (36), 497 - 522 DOI: https://10.4067/S0718-656820130003 000 
Mundo Agrario, agosto-noviembre 2019, vol. 20, n 44, e119. ISSN 1515-5994

\section{Notas}

1 http://wef.infor.cl/comercio/comerciointernacional.php 